\title{
Hard Copy
}

\author{
Jo Stockham \\ Royal College of Art \\ Dyson Building \\ 20 Howie Street \\ London SW11 4AS \\ UK \\ jo.stockham@rca.ac.uk
}

In 2014 I curated an exhibition The Negligent Eye at the Bluecoat Gallery in Liverpool as the result of longstanding interest in scanning and 3D printing and the role of these in changing the field of Print within Fine Art Practice. In the aftermath of curating show I will expand on this material with reference to the writings of Vilém Flusser and Hito Steyerl.

The work in the exhibition came from a wide range of artists of all generations most of whom are not explicitly located within Computer Arts. Whilst some work did not use any scanning technology at all, a shared fascination with the particular translating device of the systematizing 'eye' of a scanning digital video camera, flatbed or medical scanner was expressed by all the work in the show. Through writing this paper I aim to extend my own understanding of questions, which arose from the juxtapositions of work and the production of the accompanying catalogue. The show developed in dialogue with curators Bryan Biggs and Sarah-Jane Parsons of the Bluecoat Gallery who sent a series of questions about scanning to participating artists. In reflecting upon their answers I will extend the discussions begun in the process of this research.

A kind of created attention deficit disorder seems to operate on us all today to make and distribute images and information at speed. What value do ways of making which require slow looking or intensive material explorations have in this accelerated system? What model of the world is being constructed by the drive to simulated realities toward ever-greater resolution, so called high definition? How are our perceptions of reality being altered by the world-view presented in the smooth colourful ever morphing simulations that surround us? The limitations of digital technology are often a starting point for artists to reflect on our relationship to real-world fragility. I will be looking at practices where tactility or dimensionality in a form of hard copy engages with these questions using examples from the exhibition.

Artists included in the show were: Cory Arcangel, Christiane Baumgartner, Thomas Bewick, Jyll Bradley, Maurice Carlin, Helen Chadwick, Susan Collins, Conroy/Sanderson, Nicky Coutts, Elizabeth Gossling, Beatrice Haines, Juneau Projects, Laura Maloney, Bob Matthews, London Fieldworks (with the participation of Gustav Metzger), Marilène Oliver, Flora Parrott, South Atlantic Souvenirs, Imogen Stidworthy, Jo Stockham, Wolfgang Tillmans, Alessa Tinne, Michael Wegerer, Rachel Whiteread, Jane and Louise Wilson.

Scanning. Art. Technology. Copy. Materiality.

\section{INTRODUCTION}

The philosopher Flusser (1985a) begins his book Into the Universe of Technical Images with a warning:

We live in a utopia that is appearing, pushing its way up into our surroundings and into our pores... Utopia means groundlessness, the absence of a point of reference... Taking contemporary technical images as a starting point we find two divergent trends. One moves towards a centrally programmed totalitarian society of image receivers and image administrators, the other toward a dialogic, telematics society of image producers and image collectors.

In the essays that form the book, Flusser circles the themes of dread and promise which accompany our ever increasing reliance on digital tools and the information sharing across boundaries of time and space which they enable. How one might in a modest way retain a sense of agency in relationship to technology is one subject of this paper. A scanner is a mediating tool relatively 
unexamined, an invisible part of a chain of relations. However the difference from camera capture and the handheld nature of newer scanners, now within the price range of artists presents us with new creative possibilities. I am very aware that by focusing on work related to printmaking and scanning I am not presenting the growing body of work which involves 3D capture such as the work of an artist like Oliver Laric whose $3 \mathrm{D}$ scan of a $19^{\text {th }}$ century sculpture appears of the cover of Frieze magazine. His work opens up new areas of thinking about the copy, the archive and the physical, which go beyond the scope of this paper.

\section{Curating the Scan}

The Negligent Eye exhibition, shown at The Bluecoat Gallery in Liverpool in 2014 was a chance to think about these themes by gathering together artworks that focus on human/technology relations. My curiosity about scanning technology and the contradictions thrown up by even the definition of the word 'scan' as a kind of attention - both a close reading and a quick glance - led me to search out work which seemed to contain some aspect of this ambivalent curiosity and ask questions about the affect of technology and how it impacts on our sense of the everyday.

To look at the work in The Negligent Eye in 2015 is to see through eyes condition by the processing of Photoshop and the complete integration of scanning into the fabric of our social, medical and political and art/design worlds. Even works such as the postcards in the exhibition by South Atlantic Souvenirs, made in 1991 before the widespread commercial availability of photo-shop, now appear photo-shopped just as the shaping tools of CGI effects are retroactively (and wrongly) applied when viewing of films such as 2001 Space Odyssey.

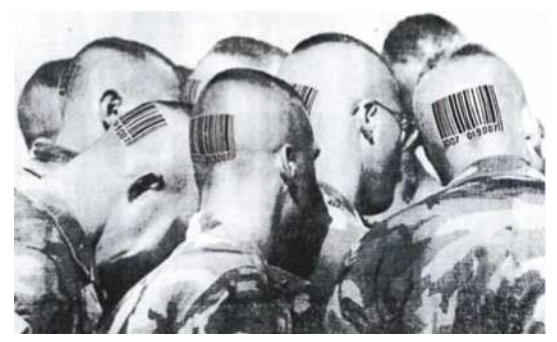

Figure 1. South Atlantic Souvenirs Individuality (1991) Postcard

My first 'computer' was an Amstrad word processor bought in 1989 with no capability for making images. Ten years later a Tangerine iBook G3 began my seeming dependence on a brand and the cycle of constant upgrading, which now dominates my working life and the distribution and production of much of my work. My first use of a scanner was to copy analogue documentation of my artwork. Though involving a loss of quality it increased my ability to share material, and complicated my relationship to any notion of an original as the endless shifting of formats make it easy to lose the first scan.

When searching out the history of scanning I came across reputedly the first scanned image. The first image scanner developed for use with a computer was a drum scanner, built in 1957 at the US National Bureau of Standards by a team led by Russell A. Kirsch. The first image scanned on this machine was a $5 \mathrm{~cm}$ square photograph of Kirsch's then-three-month-old son, Walden. I was struck by the fact that the inventor of the scanner chose to use an image of his young son for the test.

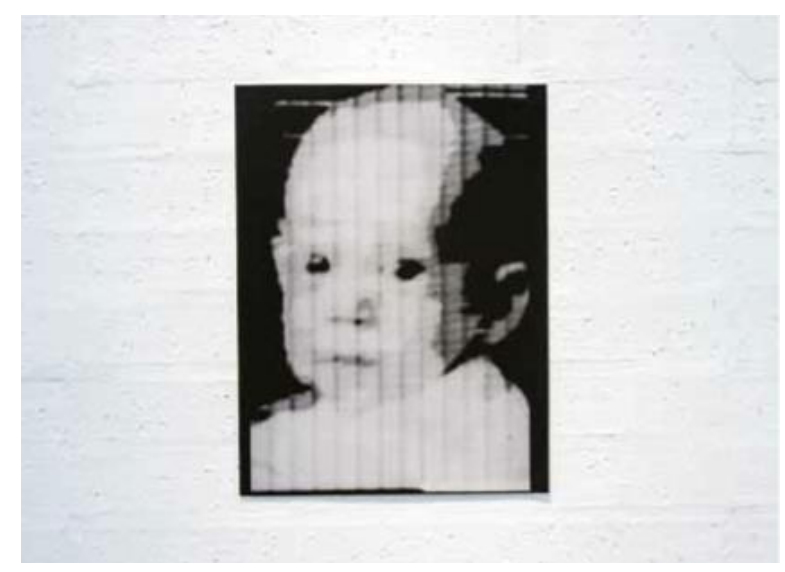

Figure 2: Pioneering digitally scanned image of Russell Kirsch's son Walden, 1957

Many of the narratives of technological history have set the human against the machine, but it seems to me that we often firstly use technologies - the pencil, the camera, writing itself - to hold onto and create images of the people and things we love. And indeed a look at the consumer market for all digital tools would bear out the fact that this aspect of sharing images of family and friends is a driving commercial force.

In many ways scans are often crude copies, and we have become accustomed to poor print quality in many magazines and catalogues but perhaps this is not the point. As Steyerl (2013) writes in In Defense of The Poor Image: one chapter of her book The Wretched of the Screen:

\footnotetext{
The condition of the images speaks not only of countless transfers and reformatting's but also to the countless people who cared enough about them to convert them over and over again, to add subtitles, reedit or upload them.
}

The act of saving an image thus becomes a form of added value, a traceable sign that they have been liked. Appropriation of an image pulled from a TV 
screen, as in Elizabeth Gossling's (2011) Ventriloquist (Dan Horn \& Orson), attests to this care and interest.

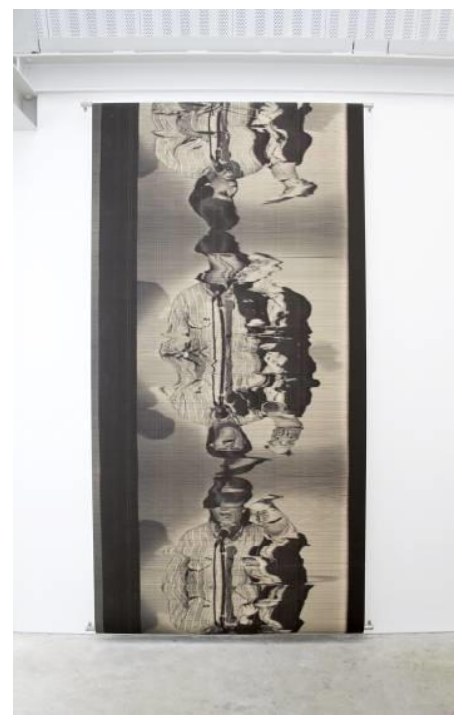

Figure 3: Elizabeth Gossling, Ventriloquist (Dan Horn \& Orson) (2011) Digital print on archival paper

The image was achieved by dragging a handheld scanner up and down the surface of a computer screen, which was streaming a ventriloquist's performance from an open source site. In the exhibition catalogue Gossling (2011b) wrote:

The ventriloquist in the performance was using his hand to speak, the dummy was his vehicle. My own hand had replaced my eyes in the act of looking... An eyeballing between two technologies had produced friction, revealing a fragile arrangement of stress fractures and digital striations.is a quotation.

The scanner performs a kind of ventriloquism the noise of the screen reads almost sonically. Copied from a reproduction of a painting another kind of appropriation operates in the work of Nicky Coutts (2006).

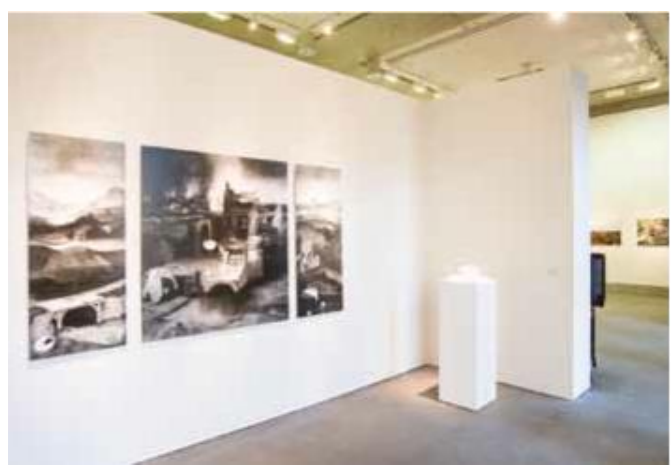

Figure 4: Installation view, Nicky Coutts Another land 3 (2006) C-type print on aluminium.
The evacuation of the figures from the Bosch landscape, a kind of visual neutron blast has removed the colour and human life from the image. This is achieved by painstaking work with photoshop, an act that requires the kind of close attention to detail, which is one definition of the word scan.

The freedoms of being able to upload, copy, reedit, circulate and browse create new communities and potentially re-politicises the image. Steryl (2013b) likens the poor image of a mobile phone, screen-grab, You-tube clip, etc. to

\section{Carbon-copied pamphlets, cine-train agit-prop films, underground video magazines and other nonconformist materials'}

The poor quality of the image often evokes a certain immediacy of content and potential questions of the status and ownership of images. But in the endless flow of images which accompany every move on the computer, to choose an image, to print save or transform it, is to stop the flow, to become in Flussers (1985b) terms, an envisioner.

The selection of work in the exhibition reflected my interest in the ways a scan is a particular kind of translation that produces data, which can then take many forms. This data capture is essentially not visualy predetermined by the eye of the maker, the handheld machine, the surveillance camera, the flat bed or body scanner all in a sense become a substitute eye, often capable of seeing what is unavailable to the naked eye.

This is so with the scanning electron microscope, which captured the tiny gallstones of Beatrice Hendry's grandmother in her work Heavenly Bodies

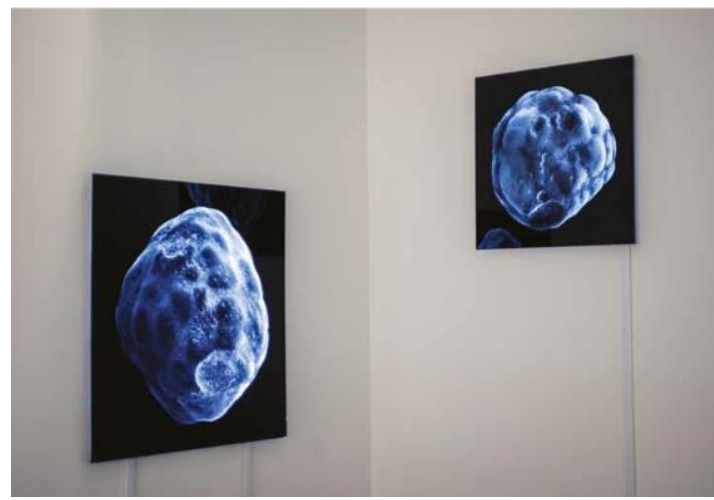

Figure 5: Installation view of Beatrice Haines Heavenly Bodies I and II (2010) at the Bluecoat Backlit scanning electron micrographs

Likewise the MRI scanner that circled each member of Marilène Oliver's family created code, which needed visualising by the artist in her bid to reprint them and reconstruct the family unit. 


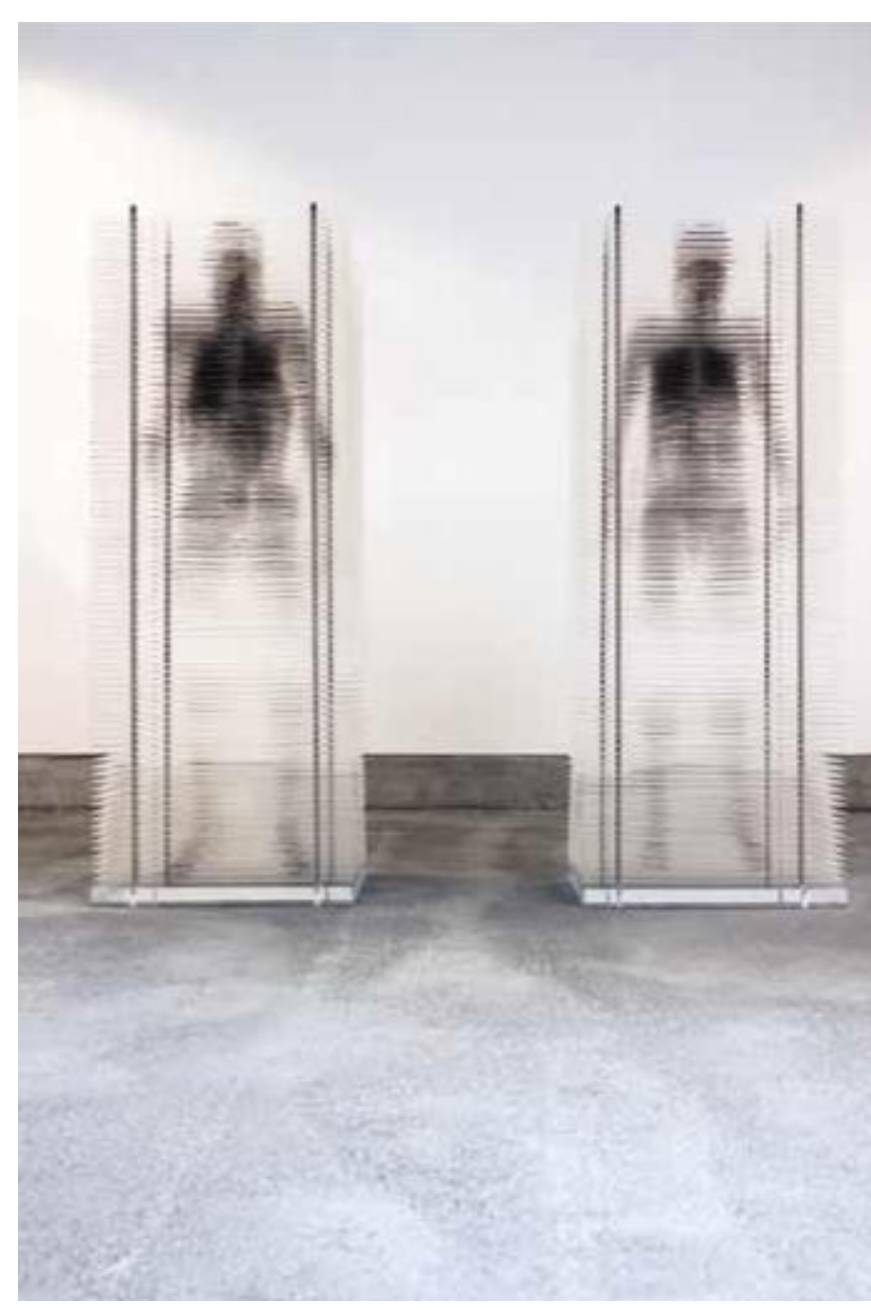

Figure 6: Installation view of Marilene Oliver Family Portrait (Mum and Dad) (2003) at the Bluecoat Screen prints on clear acrylic, bronze rods..

In the exhibition catalogue for the Negligent Eye Oliver (2014a) wrote;

By laying bare the mechanical digitisation of the body on sheets of clear acrylic my aim was to expose the gaps, the loss, the trappings of the formal mechanism but also the magic; the promise that we can be everywhere and nowhere, potentially anytime and forever.

Though physical these screen-printed stacks of body-data appear to dissolve and shift when approached by a viewer. The spectral nature of a body which disappears as one gets closer to it perhaps bringing to mind the space time travel imagined in star trek and the ultimate failure of such imaginings. It also corresponds to the experience of enlarging a digital image on screen where the effort to see closer often reveals only the structuring matrix of the image.

Oliver (2014b) wrote of how her perceptions of the technologies she uses have been profoundly changed since her move to live in sub-Saharan Africa:

I find myself struggling with a new understanding of the medically scanned body. I now recognise its strong symbolic resonance signifying privilege in terms of wealth and access to digital technologies that is far from global.

That there exist populations with little access to these tools and the freedoms of the virtual, which many of us take for granted are not evenly distributed is easy to forget from the perspective of this institution in London.

Virtual boarders also exist in the circulation information and physical boarders are sites where the concentrated development of face recognition software in use at airports involves the scanning of entire populations on the move. Jane and Louise Wilson's print False Positive, False Negative explores a desire to avoid capture by such technologies. Printed at Dundee Contemporary Art the reflective nature of the image further muddles the reading of this print. Like the camouflage used on warships this face paint confuses the scanner and allows the urban activist to merge like a moth into shadows and soot of the built landscape.

The earliest image in the exhibition was a tiny print by Thomas Bewick (1790). A fingerprint exists as the centrepiece of a landscape. The whorls and ridges of this engraved fingerprint provide cover for a miniature horse and rider and it sits outside a cottage as a digit monument, a kind of Rossetta stone to be read. Bewick perhaps already recognised, as someone who engraved and understood the nuance of line, that the particular patterns of fingerprint ridges created a unique form of identification equal to a signature. That this remains such a core aspect of identification, though now perhaps replaced by the iris, is testament to the kind of time travel which images allow us to take, and that the web allows in the shuffling and juxtaposition of any web image selection. The first attempts to produce fingerprint scanners initially failed because variables such as how hard the finger was pressed on the scanner, the grease in our bodies, and an association with criminalisation made the move unfeasible and unpopular. Now adopted in phones alongside alarming stories of severed finders, there are reports that the id can be faked if the fingerprint is printed out and used to make a template.

Helen Chadwick's Viral Landscapes mapping the hugely magnified tissues of her body onto personally significant landscapes also appeal to this question of our material selves and the scale of the individual. Reminding us we exist between the microscopic and macroscopic, this image of the fluidity of human flesh merged with a 
land/seascape into which the matter of the body returns after death evokes complex questions of origin and connection.

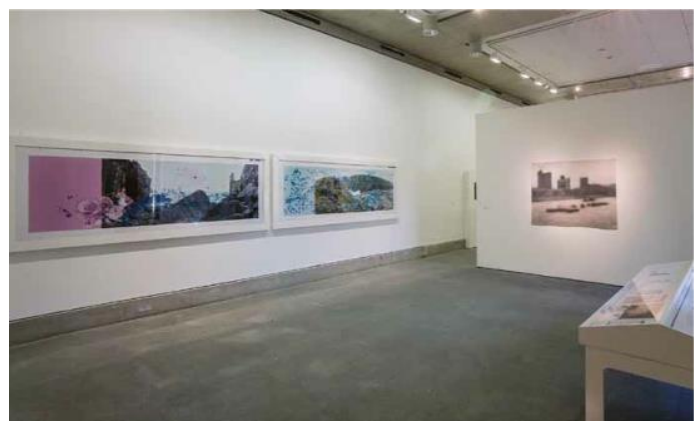

Figure 7: Installation view of Helen Chadwick, Viral Landscape no. 1 / no. 5 (1988-89) at the Bluecoat Cprint photographs, powder coated steel frames

Some works exploit scanning explicitly, like the brain scanning of artist Gustav Metzger by London Fieldworks and the subsequent shaping of materials - stone and printed nylon - by the algorithms of these data thoughts. I asked the artists to display the small 3D print-outs which to them had just been tests for a stone carving. The positive and negative spaces create a model, an absurd souvenir, of two shapes of the captured thoughts. These echo each other like a puzzle, a chicken/egg conundrum since one is logically the inside of the other but the method of construction is not a cast and so I would argue represents a new set of questions and potentials for artists and philosophers beyond its commercial application.

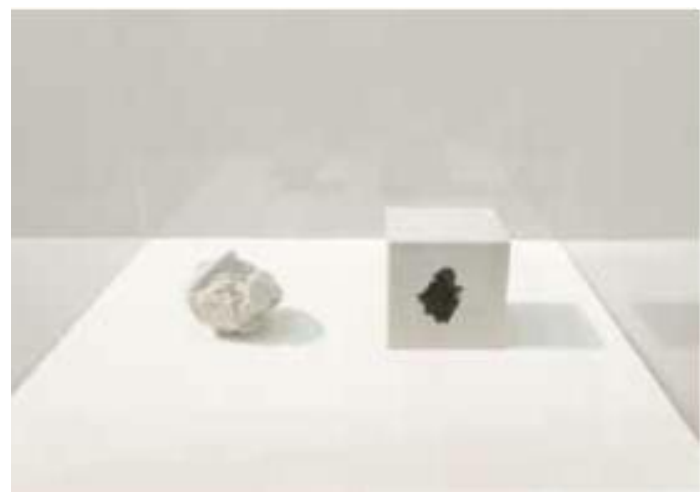

Figure 8: London Fieldworks in collaboration with Gustav Metzger .Null Object: Gustav Metzger thinks about nothing (2012) 3D printed objects

The work in the show by Wolfgang Tillmans (who famously bought a photocopier on winning the Turner prize) is another kind of visual puzzle. By representing a virtual piece of paper on an actual piece of paper the conundrum of the location of the ground of an image, a question of illusion and its pleasures is beautifully expressed. Though not directly scanned the shadowy three dimensional nature of the furled sheet of paper attests to the way in which a scanned image can appear more three dimensional than a photographed image, the flat light of the scanner creating a rendering almost like a data cast.

The dragging to destruction of a flatbed scanner by Juneau Projects (2004) across the grass and mud of a garden at night until the machine crashed highlights the technology, only to undermine it or test its limits. Their work Good Morning Captain challenges our fantasies of being able to effectively capture the natural world digitally.

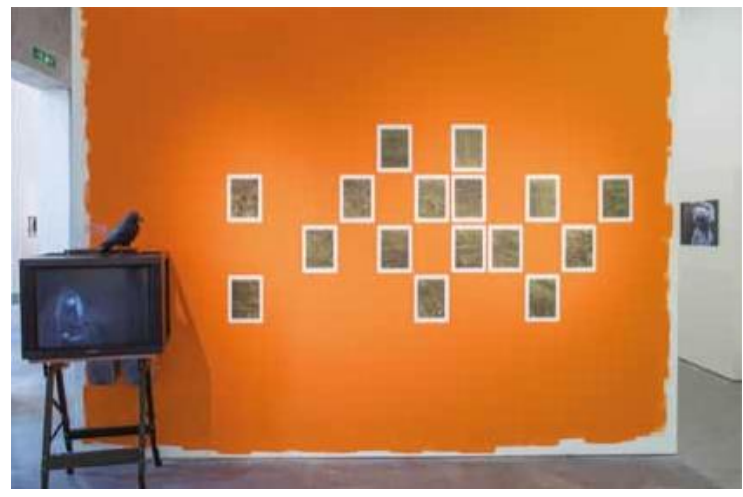

Figure 9: Installation view of Jeaneau Projects, Good Morning Captain (2004) at the Bluecoat DVD and crow 16 digital prints

There is a beauty in the created glitches and traces of plant life both squashed and revealed by the beam of the machine and an irreverent humour. Installed as a series of samples, on a painted orange wall the scans are printed out on cheap paper and a TV monitor records the image capture at night. The banding of the image samples confuses viewers as it seems to reconstruct the surface as stratification, mimicking depth.

Other work also explored the nature of damage, something, which happens in the real world but can be edited out in the virtual one. My own work Never Home (almost home reclaimed) re-claims a scanned, digitally enlarged and printed analogue photograph by touching-in, with a fine paintbrush, the cracks in its material surface.

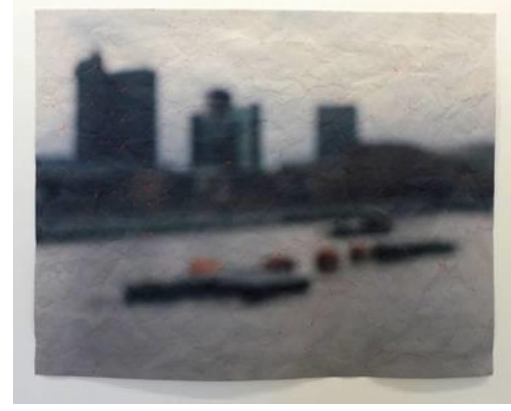

Figure 10: Jo Stockham Never Home (almost home reclaimed) digital print on banner paper 2013 
In this more oblique approach to scanning, a scanner is both a tool to copy an existing image and as a kind of close attention, a form of tracing, given to a broken surface.

The transformation of the worlds of production by scanning for rapid prototyping extend the mutability already recognised in new materials and methods in the 1930's. For my screen-print, 'any which way, (speak modernity')

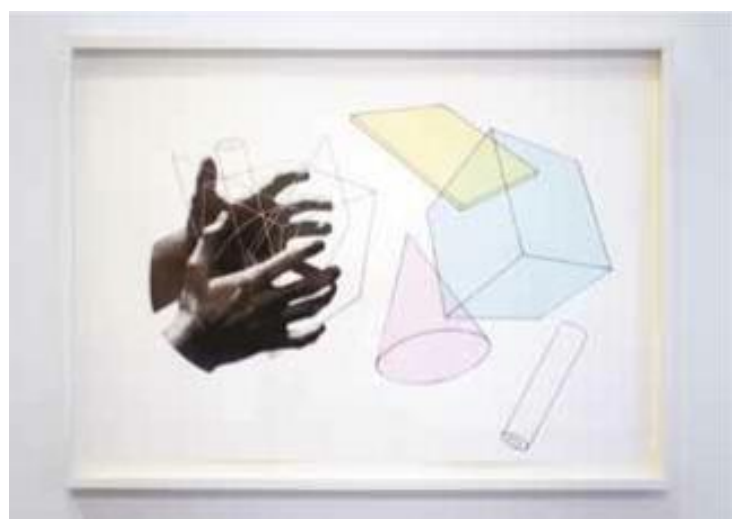

Figure 11: Jo Stockham any which way ('speak modernity') (2013) Screen print

I scanned and extended an image of hands holding the virtual forms of Bakelite plastics available in any colour and any shape from a 1930s advert. The image appeared in a magazine promoting industry in the British colonies. The spread of ways of making and their intertwining with ways of thinking is now harder to place with the way information is scanned and products on a computer screen are radically displaced. The image bought to mind Barthes' (1987) essay Plastic, a material that as a protean shape shifter can become:

buckets or jewels... Hence a perpetual amazement, the reverie of man at the sight of the proliferating forms of matter and the connection he detects between the singular of the origin and the plural of the effects... The hierarchy of substances is abolished, a single one replaces them all, the whole world can be plasticized and even life itself since, we are told, they are beginning to make plastic aortas.

Is the algorithm the plastic of today? What will become printable in the future? Human tissue can already be printed, and the anonamised datasets of the human body such, as Melanix, which Marilène Oliver used for her work Durga are freely available online.

I see this materialisation of data and its availability as an instance of the particular possibility Flusser (1985c) predicted when he said it will become the work of everyone, no longer a specialist task, to gather this abstracted quanta:
So that we may again experience it, recognize it, act in it.

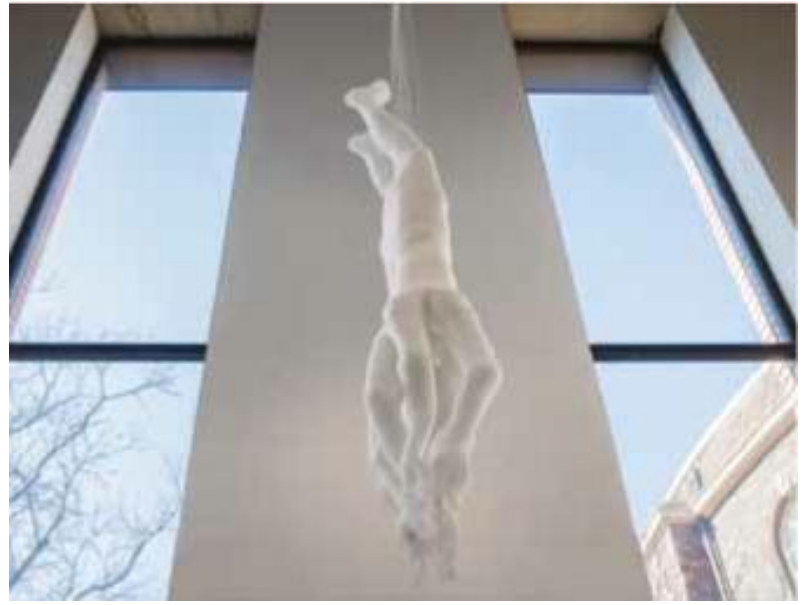

Figure 12: Installation view of Marilene Oliver, Fallen Durga (2010) at the Bluecoat Corrugated plastic

3D or stereo-lithographic printing is a way of envisioning, of editioning multiplies from scanned or CGI data. You can have your head printed in chocolate, replica guns are in circulation, and an advert for the world's first 3D doodling pen recently dropped through my letterbox (looking very like a glue gun). To see a 3D printer in action is to see an object appear as if written by magic, its plastic, shaping space lava invisibly guided by a flow of captured or constructed data. The effect is one of simultaneous creation and erasure as the complex qualities of a scanned object are unified into the non-specific material of chalky plastic or metal. Rachel Whiteread's (2004) Second-hand is a scanned stack of old dolls house furniture, which becomes an oddly fused prototype, a sci-fi fossil formed by the accumulated layers of nylon. Multiplied in an edition of 400 , it escapes the site specificity of her furniture and room casts to circulate as a model, which could be printed as an indefinite edition.

This exhibition was planned partly using a virtual model built in Sketch Up of the Bluecoat's galleries, which allowed me to position works and map out the space from a distance. This useful open source tool did not however prepare me for the material particularities, scale and weight of the works when they arrived in the space. Also being a novice user I found myself building plinths, which inserted themselves down through the floor and lost works as they floated in the virtual ether when I thought I had pinned them on walls. I had entered a world where my tacit knowledge accrued through handling materials, building walls and making objects was of no use to me at all. What is the kind of indexical relationship between an object scanned and a data cloud of that object? 
Moholy (1939a) in her book $A$ Hundred Years of Photography describes the invention of halftone printing, the breaking up of an image into dots, which replaced engravings in illustrated magazines and allowed for the mass distribution of the photographic image in newspapers in the 1890s. From dot to pixel is a short step and the structuring of images by CYMK, once specialist knowledge, is now widespread as we purchase these colours for our home printers. The levelling of all kinds of images to the same dot matrix of the halftone is itself a form of coding. Moholy (1939b) uses her last chapter to explore the distribution of images by the then new picture telegraphy significantly demonstrating an awareness of issues of distribution which have become ubiquitous:

\begin{abstract}
Pictures travel by road, by rail, by ship, by plane and in the last few years over the wire and through the atmosphere by picture - telegraphy. Any kind of picture clear enough to be photographed or re-photographed can be transmitted. Not only photographs but also fingerprints, cheques, handwriting, signatures, plans, drawings, layouts, fashion pictures, advertisements, balance sheets.
\end{abstract}

The breaking up of any image or sound information into zeros and ones is pre-given for most forms of distribution today. Scanning satellites surround the earth, and in the UK we live in one of the most densely scanned urban matrices in the world. Might it be that the notion of scanning as a quick glance, a way to surf the Internet, and the problem of making choices about what is significant, is resulting in a perpetual attention deficit disorder? What are the tools analysing Big Data doing to the way we understand the world and communicate with each other?

Moholy (1939c) ends her book on photography with a reflection:

Life without photographs is no longer imaginable. They pass before our eyes and awaken our interest; they pass through the atmosphere, unseen and unheard, over distances of thousands of miles. They are in our lives, as our lives are in them.

Life without scanners is no longer imaginable, they are in our lives and our lives are in them in ways that will continue to emerge. The data they produce presents us with new issues of reading, scale, materiality and quantity as the image world surrounds us and demands our attention 24/7.

The implications of this saturation are the subject explored by Crary (2013) in his book 24/7. The sleeplessness and changing temporality caused by our engagement with digital information and communication systems, which operate without rest makes the slow reading time of much of the work I have discussed seem from another era of attention even though most of the work is recent. The effect on our bodies of our uploaded and image hungry selves and the often static screen-bound nature of many working lives seems at such variance with the freedoms of speed and movement which digital technologies promise. The real time experience of an exhibition or event perhaps allows us to recognize our doubled lives.

Most of us have a parallel data body, the combination of our hospital records, our shopping and browser habits, which we consent to being collected by our use of various media are which is now shared and distributed in ways impossible to contain. The magic with which we invest the virtual coincides with increasing anxieties about privacy and safety. Perhaps the images that we capture in fact capture us, and our time, The Negligent Eye was a small gesture, a material glance at our entrapment, our enchantment.

Thank you for listening.

\section{REFERENCES}

Barthes, R. (1987) Mythologies, Paladin, London.

Crary, J. (2013) 24/7 Verso, London/New York.

Moholy, L. (1939) A Hundred Years of Photography 1839-1939, Pelican, London.

Steyerl, H. (2013) The Wretched of the Screen. Sternberg Press, Berlin.

Stockham, J. \& Faust, C. (2014) The Negligent Eye Bluecoat Gallery, Liverpool.

\section{PHOTO CREDITS}

Jon Barraclough. Individual copyright courtesy of the artists except Figure 2:

http://commons.wikimedia.org/wiki/File:NBSFirstSc anlmage.jpg (retrieved 20 March 2015).

Courtesy of NIST (National Institute of Standards and Technology), USA.

\section{INTERNET RESOURCE}

http://www.frieze.com/issue/article/iconoclash/ retrieved 20.03.2015 